\title{
The Influence of Styles of Family Education on Emotional-volitional Sphere of the Senior Preschool Children
}

\author{
Natalya N. Doronina, Elena I. Ziborova, Igor A. Kucheryavenko", Olga E. Panich, \\ Maria A. Reznichenko, Sergey V. Shkilev \\ Belgorod State University, Russia
}

Received July 22, 2019; Revised September 21, 2019; Accepted September 30, 2019

Copyright $(2019$ by authors, all rights reserved. Authors agree that this article remains permanently open access under the terms of the Creative Commons Attribution License 4.0 International License

\begin{abstract}
The article discusses the style of family education as its most important characteristic, the most inherent ways of attitude of parents to a child, using certain means and methods of pedagogical influence, which are expressed in a peculiar manner of verbal circulation and interaction. The formation of his/her emotional-volitional sphere will depend on these methods of parental influence on a child. When studying the style of parental education, it was revealed that fathers, unlike mothers, more frequently use the authoritarian style of family education, manifested in unreasonable demands, rigor, and lack of cooperation in the education of a child. Mothers tend to include in relation to older preschoolers a liberal style of family education, which is manifested in reduced demands, control, and emotional acceptance of the child by the parent and cooperation.
\end{abstract}

Keywords Parent-Child Relationships, Family Education Style, Emotional-volitional Sphere of Senior Preschoolers

\section{Introduction}

For a young child, the family is a whole world in which he/she not only lives, but also develops, makes discoveries, learns to rejoice and love. After all, it is in the family that the foundations of the child's personality are laid. He/she also gents the first life experience, makes his/her first discoveries in the family. The things the child has been able to acquire are laid in his memory and persist throughout his/her life. An important feature of the family is that the child is in it for a considerable time in his/her life. Depending on the special educational significance of the family, there is a problem how to act in order to maximize the positive impact and minimize the negative impact of the family on the education of the child. In this regard, it is necessary to accurately determine the intra-family socio-psychological factors with educational significance.

The most important feature of family education is its style, i.e. the most inherent ways of attitude to the child by parents, applying certain means and methods of pedagogical influence, which are expressed in a peculiar manner of verbal circulation and interaction [Zakharova and Strogalin, 2005- Kulakova, 2009]. The formation of his/her emotional-volitional sphere will depend on these methods of parental influence on a child.

A.L. Wenger defines the very concept of parenting as a style of relationships with a child in a family, characterized by a degree of control, care and guardianship, tightness of emotional contacts between parents and a child (emotionally warm - emotionally cold), control nature of behavior of a child by adults (democratic - authoritarian), number of prohibitions (restrictive -permissive), etc. [Wenger and Pilyugina, 2011; Abbasi, \& Zare, 2016].

I.M. Markovskaya in her monograph "The Psychology of Parent-Child Relationships "says that the style of family education most often means the system of methods and techniques of educational behavior of parents, due to their personal qualities and serving as a means of effective adaptation to objective requirements [Markovskaya, 2007].

As D. Baumrid believes that one need to learn to balance between the degree of control over the child and spiritual warmth in order to master the art of education. In other words, the difference between family education and social education is the emotional form of the relationship between parents and child [Baumrind, 1971].

English psychologist J. Bowlby identified two styles of parenting: democratic and controlling based on such criteria as parental control, parental requirements, 
assessment methods, emotional support [Bowlby, 1995].

Preschool age, like no other, is characterized by dependence on an adult, and the passage of this stage of personality formation is largely determined by how the child's relationship with the parents develops [Aysen and Gregory, 2006 - Ginott, 2007]. But, despite the persuasiveness of this fact, there is no data on the nature of the influence of the style of family relationships on the emotional-volitional sphere of older preschoolers, which has led to the relevance of our research.

The study purpose is to study the influence of family education styles on the emotional-volitional sphere of older preschoolers.

The style of family education is one of the fundamental factors in the development of the emotional-volitional sphere of the personality of older preschoolers. In our study, we were based on the position of D. Baumrind, who singled out the following styles of family education: authoritative, authoritarian, liberal, indifferent. The authoritative style of family education, manifested in emotional intimacy, cooperation with the child, support for his/her autonomy and consistency in the presentation of demands, will contribute to the differentiation of the emotional sphere, endurance and decisiveness. The liberal style of family education, manifested in the absence of control and cooperation, non-consistency, gentleness, will increase ambivalence in the expression of emotions and hinder the development of independence and decisiveness [Baumrind, 1971; Sears, 2018].

We suggested that family education styles can influence the formation of emotional and volitional sphere of a senior preschooler, namely: an authoritative family education style will increase stamina and determination, while a liberal family education style will increase ambivalence in the expression of emotions.

\section{Research Methods}

The choice of methods and specific research techniques for obtaining the necessary information was carried out in accordance with the goals and objectives of the work.

The study used the following methods:

- $\quad$ organizational (comparative);

- empirical (survey);

- methods of mathematical-statistical data analysis and qualitative description: Mann-Whitney criteria, correlation analysis using the Spearman correlation coefficient, multiple regression analysis (MKA), using the SPSS-21.0 mathematical statistical data package.

Research methods: "Family Education Strategies" by S.S. Stepanova, questionnaire for the study of parents-children interaction (PCI) by I.M. Markovskaya, projective test by O.A. Orekhova "Houses", technique developed by R.M. Gevorkyan "Features of Will

\section{Manifestation in Preschoolers".}

\section{Results and Discussion}

The study was conducted on the basis of the Municipal Pre-School Educational Institution No. 22, Severny settlement, Belgorod District, and the Private Pre-School Educational Institution "Goodwin "in Belgorod. 96 persons took part in it, 32 of them - mothers, 32 - fathers, and 32 - older preschoolers.

We conducted a study of the styles of family education of fathers and mothers, the peculiarities of the interaction of parents with children of senior preschool age using the method developed by S.S. Stepanov "Family Education Strategies" [Stepanov, 2000; Akimzhano, et al 2018]. According to the "non-demandingness-demandingness" scale, $25 \%$ of parents were characterized by a high level of demandingness, that is, they are generally inclined to expect a high level of responsibility from the child, his/her diligence, diligence in fulfilling the requirements put forward to him/her. Parents may show a tendency to overestimate the capabilities of their child at a certain age, perceiving it as more capable and independent. The demandingness of the average level are preferred by $67.5 \%$ of parents in their style of interaction with the child. These data indicate that the majority of parents of the studied sample have demands to their children according to their age and abilities. $7.5 \%$ of parents showed a low level of demandingness, which probably means a lack of trust in the child because of his/her small age, lack of faith in his/her strength, and, as a result, low expectations from him/her, or a share of indifference to educational moments, or excessive employment of parents, saving their time in everything, so as not to wait until the child fulfills any demands.

According to the "softness - severity" scale in cooperation with the child, high rates were obtained in $12.5 \%$ of the subjects, which characterizes their increased severity applied to the child. Parents are afraid to spoil the child, somewhere to show more gentleness, tenderness instead of reprimand and punishment. $60 \%$ of parents chose the balance of educational measures in terms of allocated polar parameters: to be stricter for a fault, to approve good actions and help, and always listen to their intuition, try to feel and understand their child. $27.5 \%$ of parents from the sample show greater softness when interacting with the child: they are often kind, patient, can forgive many misses to the child, never raise their voices, and sometimes even lose control of the child, because the child knows that there are no consequences for disobedience and non-fulfilled requirements. The family needs a certain level of leadership and hierarchy so that everyone knows their rights and duties, respects elders and helps the younger ones.

In terms of the "autonomy - control "style of family education, we obtained the following results: $40 \%$ of parents often control their child, strive for the child to 
follow all their instructions clearly, overly care for him/her, limit his/her freedom; $40 \%$ of parents showed moderate control and gave the child proper independence, autonomy, so that the child could develop safely, be supervised, be under care, but at the same time open the world by himself/herself, choose friends, engage in independent activities.

A low level of control was revealed in $20 \%$ of parents, that is, they often give their child freedom than control him/her. It is also possible to be indifferent to the older preschooler, or to admire him/her, which can lead to the child's permissiveness and complete autonomy.

The majority of parents (90\%) described their relationships with older preschoolers as emotionally close: they treat the child as the closest person, and they believe that the child has the same attitude to them. They are sure that almost always their child shares with them the most secret and important. And only 10\% defined the degree of emotional intimacy in their family at an average level, that is, in addition to trust, warmth and understanding, there is a situational emotional distance, when a particular or both parties hide something or keep back one another, have their own secrets.

In accordance with the task of our empirical research, we identified statistical differences in the indicators of the styles of family education of older preschool children between mothers and fathers. We used the non-parametric statistical criterion U-Mann-Whitney. As a result, the following differences in the style of family education were revealed: "authoritarian "at a high level of statistical significance $($ Uemp $=4.279, \mathrm{p} \geq 0.01)$ and "liberal "at a reliable level of statistical significance (Uemp $=2.142$, $\mathrm{p} \geq 0.05$ ). This result shows that fathers, unlike mothers, more frequently use the authoritarian style of family education, manifested in unreasonable demands, rigor, and lack of cooperation in the education of a child. Mothers tend to include in relation to older preschoolers a liberal style of family education, which is manifested in reduced demands, control, and emotional acceptance of the child by the parent and cooperation. The presence of a result confirming that part of mothers show a liberal style of family education and fathers are authoritarian can manifest itself in educational confrontation, which gives rise to conflicts in clarifying relations in terms of encouragement, punishment and prohibitions from the father and mother towards the older preschooler. More than $60 \%$ of fathers and mothers use an authoritative style of family education, which is manifested in emotional closeness, optimal control, exactingness, taking into account the child's desires through cooperation with him/her, consistency in making demands.

At the next stage of our research, we conducted a more detailed study of the styles of family education by fathers and mothers, the interaction features of parents with their children of older preschool age.

According

to

the "non-demandingness-demandingness "scale, $25 \%$ of parents were characterized by a high level of demandingness, that is, they are generally inclined to expect a high level of responsibility from the child, his/her diligence, diligence in fulfilling the requirements put forward to him/her. Parents may show a tendency to overestimate the capabilities of their child at a certain age, perceiving it as more capable and independent. The demandingness of the average level are preferred by $67.5 \%$ of parents in their style of interaction with the child. These data indicate that the majority of parents of the studied sample have demands to their children according to their age and abilities. $7.5 \%$ of parents showed a low level of demandingness, which probably means a lack of trust in the child because of his/her small age, lack of faith in his/her strength, and, as a result, low expectations from him/her, or a share of indifference to educational moments, or excessive employment of parents, saving their time in everything, so as not to wait until the child fulfills any demands.

A low level of control was revealed in $20 \%$ of parents, that is, they often give their child freedom than control $\mathrm{him} / \mathrm{her}$. It is also possible to be indifferent to the older preschooler, or to admire him/her, which can lead to the child's permissiveness and complete autonomy.

The majority of parents $(90 \%)$ described their relationships with older preschoolers as emotionally close: they treat the child as the closest person, and they believe that the child has the same attitude to them. They are sure that almost always their child shares with them the most secret and important. And only 10\% defined the degree of emotional intimacy in their family at an average level, that is, in addition to trust, warmth and understanding, there is a situational emotional distance, when a particular or both parties hide something or keep back one another, have their own secrets.

In the course of our study, we identified the parameters that manifest themselves when interacting with children of older preschool age and most pronounced among parents. Namely, the average level: demandingness (67.5\%), softness - severity $(60 \%)$, moderate (along with high) control ( $40 \%$ each), anxiety for a child $(72.5 \%)$, sequence of educational influences (55\%), sometimes emerging educational confrontation in the family ( $55 \%$ of parents). The highest indicators were obtained according to the following interaction features: emotional intimacy with the child $(90 \%$ of parents), adoption of the child (72.5\%), cooperation with him/her $(67.5 \%)$ and satisfaction with the relationship with the child (72.5\%).

In accordance with the task of our empirical research, we identified statistical differences in the indicators of the styles of family education of older preschool children between mothers and fathers. We used the non-parametric statistical criterion U-Mann-Whitney.

As a result, differences were found at the level of statistical trend $\mathrm{p} \geq 0.1$ in such indicators of family 
education as "non-demandingness-demandingness of a parent "Uemp $=-1.389$, "rejection-adoption of a child by parent "Uemp $=-1.647$, "lack of cooperation-cooperation " Uemp $=-1.832$, "educational confrontation in the family" Uemp $=-1.448$. This result shows that fathers, unlike mothers, use a style that is characterized by the following features: exactingness, adoption of a child by a parent, cooperation in the education of a child.

Thus, there are differences in the indicators of the style of parental education by fathers and mothers. Mothers are more demanding, but they cooperate with the child, and fathers tend to use educational confrontation in the family. Such an indicator of family education as the "adoption of a child by a parent "is most pronounced for fathers.

Let us proceed to the description of the study results concerning emotional-volitional sphere of older preschoolers. We studied the prevailing emotional background of children and the degree of differentiation-generalization of their emotional sphere.

In $42.5 \%$ of children, the emotional background is characterized by the predominance of positive emotions, that is, their mood is mostly upbeat, joyful, they are active and sociable, they adapt quite easily in a new environment, find something to do, are natural in their emotional manifestations. In $55 \%$ of children, the emotional background is normal, that is, the child rejoices and is sometimes sad, there is no cause for concern. The predominance of negative emotions was revealed only in $2.5 \%$ of the children's sample, and these are the children who need special attention, because it is during this period that they need the support and help of adults. Their mood is reduced, they often have unpleasant experiences, the world is perceived in gray shades.

Using the $r_{\mathrm{s}}$-Spearman's rank correlation coefficient, we identified 7 significant correlations between the indicators of parent-child relationships, to which we attribute the features of parent-child interaction and the severity of symptom complexes of family situation perception by older preschoolers, as well as the features of emotional-volitional sphere. This is the prevailing emotional background, type of emotional sphere and formation of volitional qualities. In general, according to all indicators of the methods used, 18 significant correlations were found, of which 12 were positive (direct) and 6 negative (inverse).

There are connections between the predominant emotional background and such indicators as: type of emotional sphere $(r=0.320, p \geq 0.05)$ : strengthening negative emotions leads to inversion and ambivalence of the emotional sphere, that is, children express rejection of positive emotions and duality of feelings; and perseverance of older preschoolers $(r=-0.444, p \geq 0.01)$ : negative emotions (high score on the emotional background meant the predominance of negative emotions) reduce persistence in achieving goals, children cannot finish something to the end, quickly succumb to reluctance, various whims.
The high significant correlations between the type of emotional sphere and the child's moderation $(r=-0.450$, $\mathrm{p} \geq 0.01$ ) are defined, that is, the more emotional sphere is generalized (no differentiation from the second to the fourth type), the lower the child's moderation is. With the level of the sequence of educational influences of parents, a significant positive correlation was found between the indicator under consideration $(r=0.551, p \geq 0.01)$.

The child acceptance rates have a high significant direct connection with the data on the parent's sequence in interaction with the child $(r=0.424, p \geq 0.01)$ : the more the parent accepts the child as he/she is, the more often he/she is consistent in his/her actions, reactions and requirements, because he/she trusts the child, treats him/her with respect and considers him/her capable.

\section{Summary}

Thus, there were 5 statistically significant correlations between the indicators of the styles of family education and the peculiarities of emotional-volitional sphere of older preschoolers. The more parents show anxiety for the child, the lower will be his/her emotional background and endurance, consistency in interaction with the child contributes to a favorable type of emotional sphere and the development of independence of the older preschooler. The higher is the satisfaction with the child, the lower the child's moderation will be developed. This can be explained by the fact that parents who are satisfied with the relationship with the child may exhibit hyperprotection, which negatively affects the development of such volitional quality as endurance.

The results of our research and statistical data processing allowed us confirming the hypothesis that that family education styles can influence the formation of emotional and volitional sphere of a senior preschooler, namely: an authoritative family education style will increase stamina and determination, while a liberal family education style will increase ambivalence in the expression of emotions.

\section{REFERENCES}

[1] Aysen, B., \& Gregory, M. (2006). Mothers' and Fathers' Communication Style and Children's Perceived Influence in Family Decision Making. Journal of International Consumer Marketing, 19, 75-95

[2] Akimzhano, T., Amandykova, S., Tleukhan, R., Daurembekov, Y., \& Aykumbekov, N. (2018). Problems of applying and realization of preventive measures in the form of detention concerning persons, suspected and accused in the commission of the act of terrorism and crimes of extremist nature. Opción, 34(85-2), 800-823.

[3] Abbasi, M., \& Zare, A. (2016). Information Security in E-Commerce Law. UCT Journal of Social Sciences and 
Humanities Research, 4(3), 16-20

[4] Bauermeister, J. J., Puente, A., Martinez, J. V., Cumba, E., Scandar, R. O., \& Bauermeister, J. A. (2010). Parent perceived impact of spaniard boys 'and girls' inattention, hyperactivity, and oppositional defiant behaviors on family life. Journal of Attention Disorders, 14(3), 247-255.

[5] Baumrind, D. (1971). Current patterns of parental authority. Developmental Psychology, 4(1), 1-103.

[6] Bersabé, R., Fuentes, M. J., \& Motrico, E. (2001). Psychometric analysis of two scales to evaluate parenting styles. Psicothema, 13(4), 678-684.

[7] Bornstein, M. H. (2012). Cultural approaches to parenting. Parenting: Science \& Practice, 12(2-3), 212-221.

[8] Bowlby, J. (1995). Family interaction in disturbed and normal families: a methodological and substantive review. Journal of Personality, 1, 33-65.

[9] Ginott, H. G. (2007). Between parent and child. New solutions to old problems. London: Stadles Press: 178.

[10] Intaleva, V. V., \& Rivera A. I. (2017). Features of the Development of Emotional-Volitional Sphere of Preschooler. Scientific Dialogue: Young Scientist: Materials of the III International Scientific Conference. St. Petersburg, 5, 33-34 (in Russian).

[11] Ivanova, N. N., \& Myakota, T. A. (2015). The Specifics of Emotional-Volitional Sphere of Preschoolers. Actual Problems of the Humanities and Natural Sciences. Moscow, 3, 255-260 (in Russian).

[12] Kulakova, E. (2009). Studying the Emotional Well-Being of Preschooler in a Family. Obruch, 5, 11-13 (in Russian).

[13] Markovskaya, I. M. (2007). Psychology of Parent-Child Relationships. Chelyabinsk: Publishing House of the South Ural State University: 91 (in Russian).

[14] Schaefer, E. S. (2001). Development of a parental attitude research instrument. Child Development, 3, 339-361.

[15] Stepanov, S., (2000). Family Education Strategies. School Psychologist, 8, 21-22 (in Russian).

[16] Sears, R. (2018). The Implications of a Pacing Guide on the Development of Students Ability to Prove in Geometry. International Electronic Journal of Mathematics Education, 13(3), 171-183. https://doi.org/10.12973/iejme/3835

[17] Varga, A.Ya. (2001). Systemic Family Psychotherapy: a Short Lecture Course. St. Petersburg: Rech: 144 (in Russian).

[18] Weiner, M. E. (2008). Emotional Development of Children: Age Characteristics, Diagnosis and Assessment Criteria. Correctional and Developing Education, 4, 63-73 (in Russian).

[19] Wenger, L.A., \& Pilyugina E.G., (2011). Raising the Child's Sensory Culture. Moscow: Logos: 144 (in Russian).

[20] Zakharova, E. I. \& Strogalin A.I., (2005). Features of Adopting a Parental Position. Psychological Diagnostics, 4 , 58-70 (in Russian). 